\title{
South Africans' understanding of and response to the COVID-19 outbreak: An online survey
} \author{
S Sifunda, ${ }^{1} \mathrm{PhD}$; K Zuma, ${ }^{1} \mathrm{PhD}$ \\ ${ }^{1}$ Human and Social Capabilities, Human Sciences Research Council, Cape Town, South Africa \\ ${ }^{2}$ Faculty of Health Sciences, Nelson Mandela University, Port Elizabeth, South Africa
}

S P Reddy, ${ }^{1,2} \mathrm{PhD}$; R Sewpaul, ${ }^{1} \mathrm{MSc} ; \mathrm{M}$ Mabaso, ${ }^{1} \mathrm{PhD}, \mathrm{S}$ Parker, ${ }^{1} \mathrm{PhD} ; \mathrm{I}$ Naidoo, ${ }^{1} \mathrm{PhD} ; \mathrm{S}$ Jooste, ${ }^{1} \mathrm{MA} ; \mathrm{T} \mathrm{Mokhele},{ }^{1} \mathrm{PhD} ;$

Corresponding author: $R$ Sewpaul (rsewpaul@hsrc.ac.za)

\begin{abstract}
Background. The COVID-19 outbreak is in an accelerating phase, and South Africa (SA) has had the highest number of documented cases during the early phase of the pandemic in sub-Saharan Africa.

Objectives. To assess South Africans' understanding of and response to COVID-19 during the first week of the country's lockdown period. Methods. An online survey was conducted in SA from 27 March to 2 April 2020. The survey was distributed widely among several websites and social media networks, including on a data-free platform. Descriptive statistics of knowledge, risk perception, access to and trust in information sources, and public and media opinions were calculated. Estimates were benchmarked to the 2019 national adult population estimates.

Results. Of the 55823 participants, the majority (83.4\%) correctly identified the main symptoms of COVID-19. Over $90 \%$ had correct knowledge of the incubation period, with lower rates for 18 - 29-year-olds. Knowledge of symptoms and the incubation period varied significantly by population group $(p<0.001)$, dwelling type $(p<0.001)$ and sex $(p<0.001)$. A quarter $(24.9 \%)$ perceived themselves as at high risk of contracting COVID-19. Risk perception varied by age, population group, employment status and dwelling type $(p<0.001)$. The most prevalent COVID-19 information sources were government sources (72.9\%), news websites/apps (56.3\%), satellite television (51.6\%) and local television (51.4\%).

Conclusions. Understanding knowledge, attitudes and behaviours of people facing the COVID-19 pandemic is crucial for guiding strategic policy. These findings provide public understanding of COVID-19 as the phases of the country-level epidemic progress, and also directly inform communication needs and gaps.
\end{abstract}

S Afr Med J 2020;110(9):894-902. https://doi.org/10.7196/SAMJ.2020.v110i9.14838

The outbreak of the coronavirus, COVID-19, in China was declared a Public Health Emergency of International Concern by the World Health Organization (WHO) in February 2020.[1] It began as a zoonotic infection in Wuhan, China. On 11 March it was declared a global pandemic, and by 5 April, there were $>1.1$ million cases of COVID-19 and >62 000 deaths associated with the disease. ${ }^{[2]}$ Governments around the world have implemented public health and behavioural interventions to curtail the rapid spread.

Epidemic response measures have been implemented in several countries, including lockdown and containment strategies, testing and contact tracing, strengthening healthcare systems, and mobilising personal protective equipment. The behavioural strategies include hand washing, hand sanitiser use, cough and sneeze control, wearing of face masks, avoiding touching the face, cleaning surfaces, monitoring oneself for symptoms, social distancing, self-quarantine and isolation. ${ }^{[3]}$ The threat of a severe outbreak in Africa looms large, given the continent's high prevalence of communicable diseases such as HIV and AIDS, tuberculosis (TB), and malaria; increasing non-communicable diseases; and constrained health systems. ${ }^{[4]}$ Additionally, South Africa (SA) has among the world's highest HIV and TB prevalences, with many people living in overcrowded townships with inadequate access to water, sanitation and hygiene resources. ${ }^{[5]}$

The COVID-19 outbreak is in an accelerating phase in SA, which had the highest number of documented cases in sub-Saharan Africa by April 2020. The first cases were detected in the first week of March, and by 6 April there were 1686 cases and 12 deaths. ${ }^{[6]}$ Over 58000 tests were conducted. The epidemic in SA is estimated to be a few weeks behind the COVID-19 outbreaks in the USA and Europe.

SA has acted rapidly to exert control over the COVID-19 outbreak at an early stage. The SA government's response has been aligned with various global guidance, and the President declared a National State of Disaster on 15 March. Travel bans were imposed on foreigners from high-risk countries, non-essential domestic and international outgoing flights were restricted, SA citizens returning from high-risk areas were to be self-quarantined, individuals exposed to infected patients were to be traced and asked to selfisolate, and many major ports of entry were shut down. In addition, communication on prevention measures was intensified, gatherings of more than 100 were prohibited, schools were closed in midMarch, intensified hygiene control measures were implemented in workplaces and public places, and hospital capacities were strengthened. On Friday 27 March, a 21-day lock down period was imposed. ${ }^{[7]}$

\section{Objectives}

To advance understanding of the knowledge, attitudes and behaviours related to COVID-19 in SA, a study was conducted to inform policy in the early phases of the outbreak.

\section{Methods}

\section{Study design and sampling}

An online survey was conducted from 27 March 2020 to 2 April 2020, which coincided with the first 7 days of the lockdown period for 
COVID-19. An online survey method was employed, as face-to-face survey methods were not feasible. The sample comprised SA adults ( $\geq 18$ years) who had access to the internet or smart electronic devices and received the invitation to participate.

\section{Study procedures}

The request to participate in the survey was widely distributed using various communication and social media channels The survey was distributed on the datafree Moya Messaging platform, which was selected for its data-free nature and its large user base of four million members and one million daily engaged users nationally. This model allows anyone with a mobile phone to respond to the survey, regardless of available airtime or data in their mobile phone account. The platform's users are 53\% female, $20 \%$ public servants and $99.5 \%$ SA citizens, with a higher proportion of younger users. The average monthly income for $92 \%$ of the users is <ZAR15 000 (USD828). In addition, communication alerts to participate in the survey were widely distributed via numerous communication and media channels, including social media and email, and on websites.

The research team released press statements to promote participation in the survey. All participants were encouraged to share the link. The links included a standard internet link and a link for mobile phone users to access the survey at no cost. This method allowed the survey to reach South Africans across a broad economic spectrum. Survey participation was voluntary, and no personal information was required to submit a response. Participants were requested to provide informed consent. They were informed of voluntary participation, the anonymity of their responses and the option to withdraw. The average survey completion time was 10 minutes.

\section{Measures}

The questionnaire was developed through a consultative process with behavioural researchers, public health scientists and epidemiologists. The questionnaire development was informed by recent work on public opinions and reactions to the COVID-19 emergency. ${ }^{[8,9]}$ Subject areas in the questionnaire were general knowledge of COVID-19, including knowledge of symptoms, the incubation period and modes of transmission; beliefs and attitudes; risk perception; sources of information and trust therein; public opinion; and civil preparedness and response capabilities. The questionnaire comprised 48 items, of which 47 were closed-ended. Because linguistic translation services were affected by the lockdown, this first survey was only available in English.

Individual dwelling type was grouped into formal and informal dwellings. Shacks, traditional huts, tents and caravans were categorised as informal dwellings. A standalone house, house or room in the back yard, flat, and town house or semi-detached Correct knowledge of symptoms was defined as identification of cough, fever and shortness of breath from a range of multiplechoice options. Knowledge of viral mode of transmission was assessed by multiplechoice response options. Participants were asked to select all the ways in which the virus can be spread and prevented.

\section{Ethical considerations}

The study received ethical approval from the Human Sciences Research Council Research Ethics Committee (ref. no. REC 5/03/20). Contact information of senior researchers was provided to address participant queries.

\section{Statistical analysis}

Data were analysed using Stata version 15.0 (StataCorp, USA). Data were benchmarked to SA's 2019 mid-year adult population estimates by age, race, sex and province ${ }^{[10]}$ to allow generalisability of the findings to the rest of the country and correct for potential biases caused by disproportionate participation. Descriptive statistics were used to summarise correct knowledge and various attitudes and practices by sociodemographic characteristics. Unweighted totals and weighted percentages are reported. Differences in estimates across the demographic groups were compared using pairwise $t$-tests and $\chi^{2}$ tests. A statistical significance level of $p<0.05$ was used. house were categorised as formal dwellings.

\section{Results}

\section{Demographic characteristics}

A total of 55823 individuals responded to the survey, with $25.9 \%$ constituting the 30 39 -year age group; females comprised $52.1 \%$, black Africans $78.4 \%$, and those who reported full-time employment $49.3 \%$. The majority of the sample resided in three provinces: Gauteng (28.0\%), KwaZulu-Natal (18.3\%) and Western Cape (12.4\%) (Table 1).

\section{Knowledge of symptoms,} incubation period and transmission The majority of the participants $(83.4 \%)$ correctly identified cough, shortness of breath and fever as symptoms of COVID19 from the range of options (Table 2). Correct identification of the three symptoms was significantly higher among females than among males $(p<0.001)$, among coloured, white and Indian than among black African population groups $(p<0.001, p<0.001$ and $p=0.001$, respectively), and among selfemployed than among part-time employees ( $p=0.005)$.

Fig. 1 shows that cough, fever and shortness of breath were identified by $93.2 \%, 89.7 \%$ and $95.6 \%$ of participants, respectively. Body pain, which is also a symptom of COVID-19, was identified by $50.1 \%$ of participants. Red/itchy eyes, which is not a common COVID-19 symptom, was identified by $11.6 \%$ of participants.

Overall, $92.9 \%$ of participants correctly identified the incubation period as $2-14$ days. Knowledge of the incubation period was significantly lower in 18 - 29-year-olds than in $50-59$-year-olds $(p=0.024)$ and 60 - 69-year-olds $(p=0.038)$. Knowledge of the incubation period was significantly higher in white, coloured and Indian populations than in the black African population $(p<0.001, p=0.005$ and $p=0.002$, respectively), and in full-time employed and self-employed participants than in

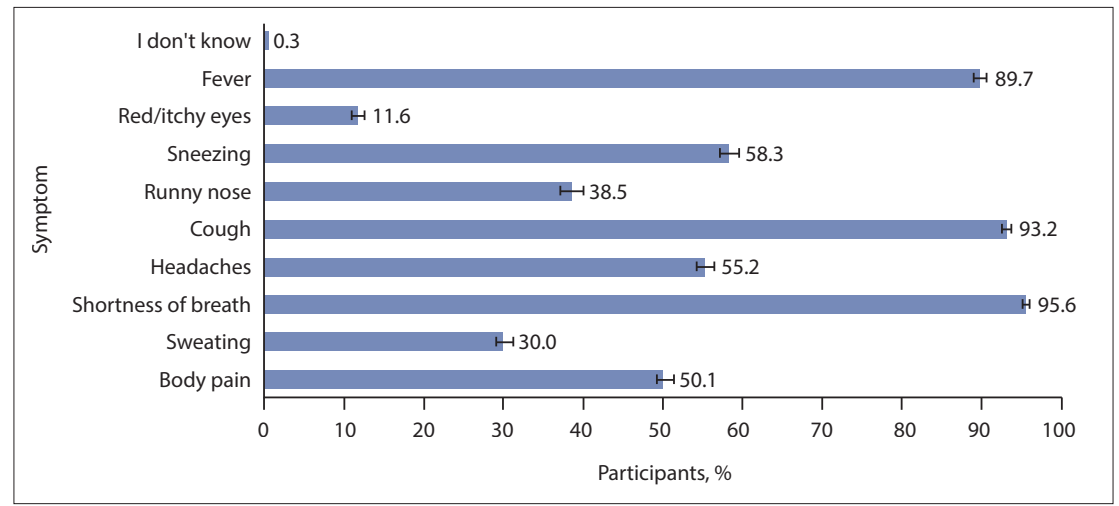

Fig. 1. Percentage of participants who selected each of the options that they thought were common symptoms of COVID-19. 
Table 1. Sociodemographic characteristics of the participants

\begin{tabular}{|c|c|c|}
\hline Variables & $n^{\star}(\%)$ & 95\% CI \\
\hline Total & 55823 & \\
\hline \multicolumn{3}{|l|}{ Age group (years) } \\
\hline $18-29$ & $9519(31.5)$ & $30.4-32.6$ \\
\hline $30-39$ & $13665(25.9)$ & $24.9-26.8$ \\
\hline $40-49$ & $13496(17.0)$ & $16.2-17.8$ \\
\hline $50-59$ & $10956(12.1)$ & $11.4-12.8$ \\
\hline $60-69$ & $6054(8.1)$ & $7.4-8.8$ \\
\hline$\geq 70$ & $1927(5.5)$ & $4.5-6.7$ \\
\hline \multicolumn{3}{|l|}{ Sex } \\
\hline Male & $16365(47.9)$ & $46.7-49.1$ \\
\hline Female & $34927(52.1)$ & $50.9-53.3$ \\
\hline \multicolumn{3}{|l|}{ Race } \\
\hline Black African & $9083(78.4)$ & $77.8-78.9$ \\
\hline Coloured & $4688(9.0)$ & $8.7-9.4$ \\
\hline White & $36878(9.6)$ & $9.4-9.9$ \\
\hline Indian/Asian & $4016(3.0)$ & $2.8-3.1$ \\
\hline \multicolumn{3}{|l|}{ Employment status } \\
\hline Employed full time & $29003(49.3)$ & $48.1-50.5$ \\
\hline Employed informal/part time & $3984(7.8)$ & $7.2-8.4$ \\
\hline Student & $3116(11.6)$ & $10.9-12.4$ \\
\hline Unemployed & $8861(20.3)$ & $19.2-21.4$ \\
\hline Self-employed & $10625(10.9)$ & $10.1-11.8$ \\
\hline \multicolumn{3}{|l|}{ Dwelling type } \\
\hline Formal & $52971(95.6)$ & $86.5-88.1$ \\
\hline Informal & $606(4.4)$ & $3.9-5.0$ \\
\hline \multicolumn{3}{|l|}{ Province } \\
\hline Eastern Cape & $2617(10.5)$ & $9.8-11.2$ \\
\hline Free State & 1339 (4.9) & $4.4-5.3$ \\
\hline Gauteng & $25553(28.0)$ & $27.3-28.8$ \\
\hline KwaZulu-Natal & $6734(18.3)$ & $17.5-19.1$ \\
\hline Limpopo & $1116(9.4)$ & $8.5-10.3$ \\
\hline Mpumalanga & $1031(7.6)$ & $6.9-8.4$ \\
\hline North West & $1045(6.7)$ & $6.0-7.5$ \\
\hline Northern Cape & $519(2.1)$ & $1.9-2.4$ \\
\hline Western Cape & $15869(12.4)$ & $12.0-12.9$ \\
\hline
\end{tabular}

students $(p<0.001)$, part-time employed $(p<0.001)$ and unemployed participants $(p<0.001)$.

When asked to select modes of viral transmission, $94.2 \%$ selected through infected persons coughing and sneezing, 91.5\% selected touching one's face after being in contact with an infected person, $84.5 \%$ selected contact with virus-contaminated surfaces, and $83.9 \%$ selected contact by being in a gathering with an infected person. Knowledge of viral transmission by coughing and sneezing was significantly lower in 18 - 29-year-olds than in all other age groups $(p<0.001)$, in black Africans than in all the other groups $(p<0.001)$, and in students and part-time employees than in fulltime employees $(p<0.001)$ and those who were self-employed $(p<0.001)$

Correct identification of touching one's face after being in contact with an infected person as a mode of transmission was significantly lower in 18 -29-year-olds than in 30 -39-yearolds, $(p=0.005), 40$ - 49-year-olds $(p=0.013)$ and 60 - 69-year-olds $(p=0.001)$, and in black Africans than in all the other population groups $(p<0.001)$. Correct identification of virus-contaminated surfaces was significantly higher in the Western Cape than in all other provinces except the Northern Cape $(p<0.05)$. Knowledge of this mode of transmission was significantly lower in 18 - 29-yearolds than in all the other age groups $(p<0.001)$, in black Africans than in the other groups $(p<0.001)$, and in students, part-time employees and unemployed participants than in full-time employed and self-employed participants $(p<0.001)$. Correct identification of viral transmission from being in a gathering with an infected person was significantly lower in males than in females $(p<0.001)$, in 18 29 -year-olds than in all other age groups $(p<0.005)$, in black African than in white and Indian participants $(p<0.001)$, and in students than in self-employed participants $(p=0.001)$.

Correct knowledge for all six items, namely the identification of cough, fever and shortness of breath as symptoms, the incubation period, and selection of all four modes of transmission, was significantly lower among participants who lived in informal dwellings than in formal dwellings $(p<0.001)$. For all the knowledge 


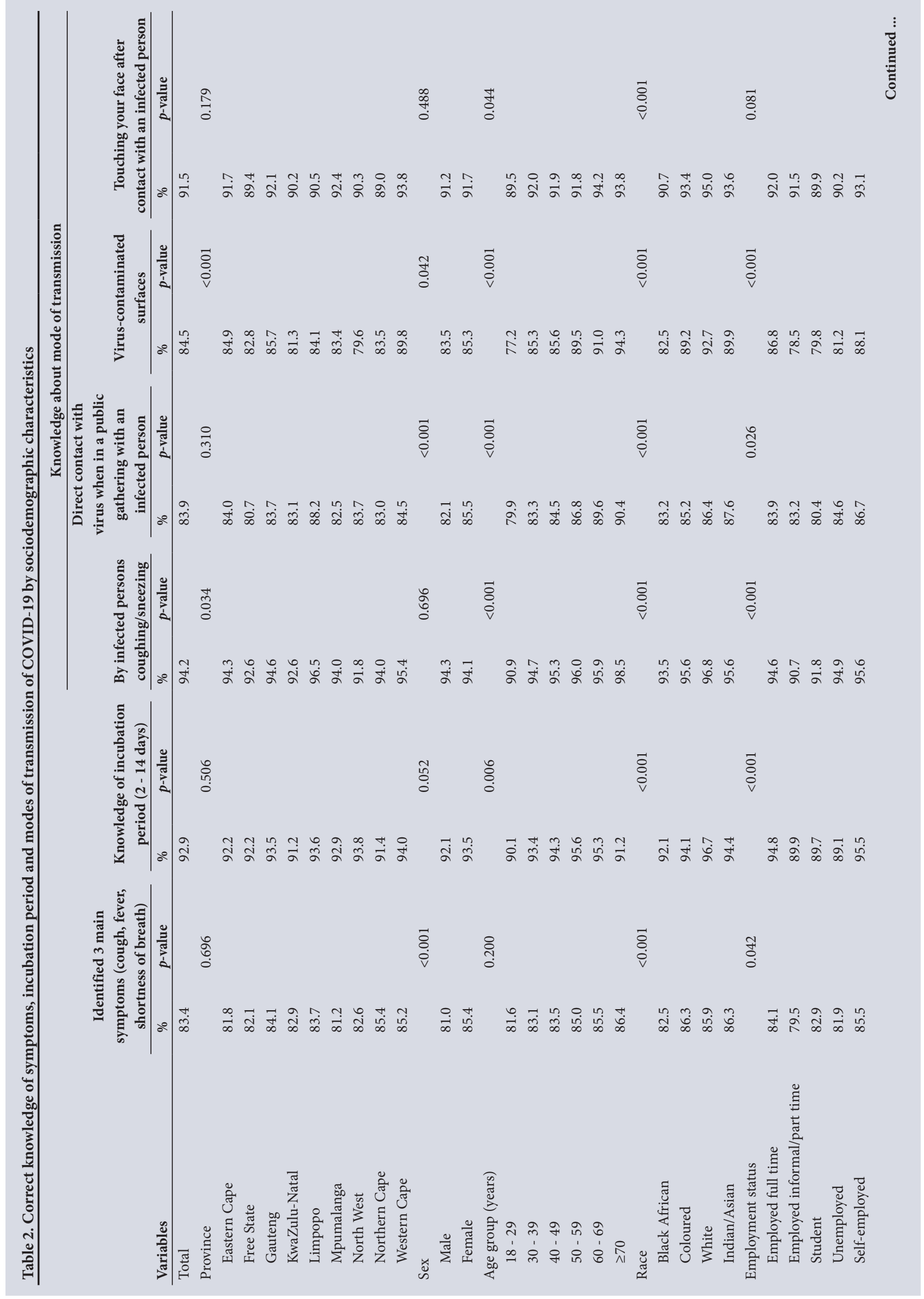




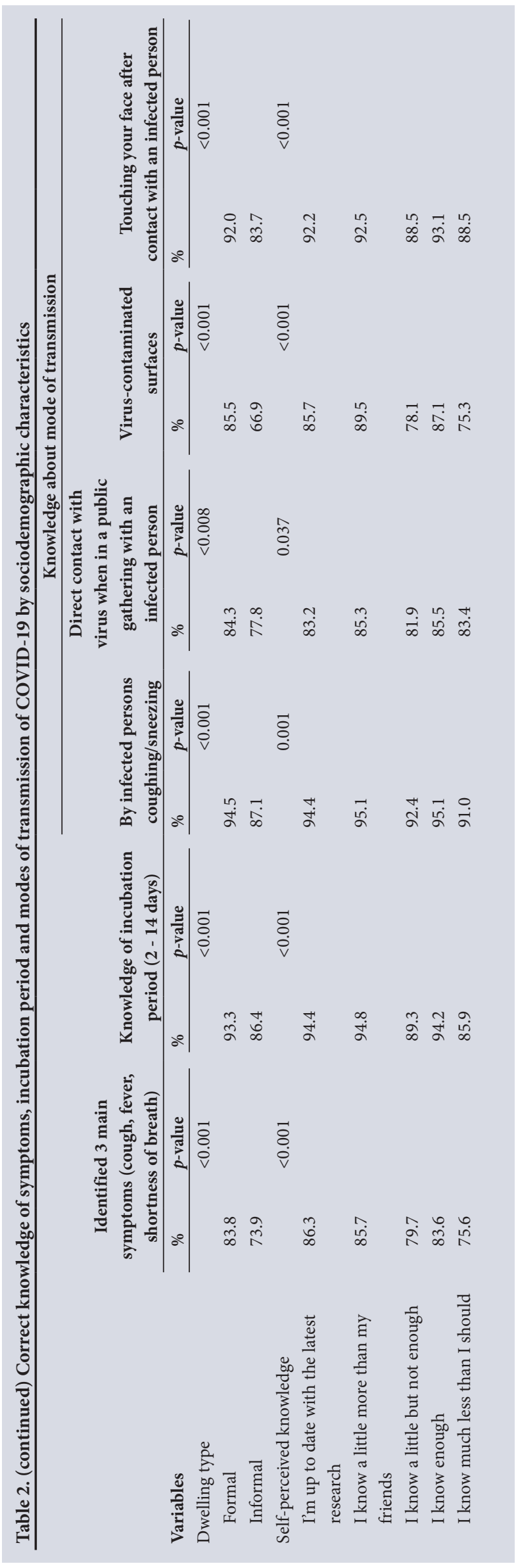

items, with the exception of transmission by being in a public gathering with an infected person, knowledge was significantly lower among those who reported that they knew a little but not enough or that they knew much less than they should know about COVID-19 compared with those who reported that they knew enough $(p<0.05)$.

\section{Knowledge of prevention measures}

Methods of prevention were correctly identified, with $97.4 \%$ of participants selecting hand washing for 20 seconds and $97.1 \%$ selecting staying at home during the lockdown period (Fig. 2). Covering the mouth with a flexed elbow when coughing was correctly identified by $92.1 \%, 70.4 \%$ and $67.0 \%$ selected wearing a face mask and gloves, respectively, while $12.3 \%$ thought that they could get vaccinated.

\section{Risk perception}

A quarter of the participants perceived themselves as at high risk of becoming infected with COVID-19, 36.6\% as at moderate risk and $38.8 \%$ as at low risk (Table 3). Perception of high risk differed by province, being lowest (22.8\%) in Gauteng and highest (30.6\%) in Free State $(p=0.006)$. The prevalence of high-risk perception was significantly lower in the youngest age group (18 - 29-year-olds) than in 30 - 39-year-olds ( $p=0.001), 50$ - 59-year-olds $(p=0.015)$ and 60 - 69-year-olds ( $p=0.001)$; in students than in all other employment categories ( $p<0.001$ for all); and in formal dwellings than in informal dwellings $(p<0.001)$. Significantly more black African, coloured and Indian participants than white participants perceived themselves as at high risk $(p<0.001)$.

Participants were asked to select reasons why they thought they were at their selected risk level. Among participants who perceived themselves as at high risk, $39.8 \%$ attributed it to their high-risk work environment, $29.8 \%$ to underlying medical conditions and $21.6 \%$ to being in a high-risk age group, while $44.2 \%$ reported that everyone is at risk (Fig. 3).

\section{Infection control and prevention behaviours during the past week}

The most prevalent infection control and prevention behaviours reported during the week preceding the survey were frequent hand washing $(95.0 \%)$, staying at home and decreasing social interaction (92.7\%), hand sanitiser use (88.9\%) and covering coughs and sneezes with a tissue or flexed elbow (78.9\%) (Fig. 4). A quarter of the participants reported wearing gloves.

\section{Sources of information and trust therein}

The most highly reported sources used by participants to obtain information on COVID-19 were government sources (72.5\%), news websites and apps (56.3\%), satellite television (51.4\%) and local television (51.1\%) (Fig. 5). Information from doctors, spouses or children, SMSs (text messages), other mobile chat services and print newspapers were the information sources least accessed.

When asked about the degree of trust they had in information from each source, $69.2 \%$ reported high trust in government sources, followed by scientific journals $(57.2 \%$ placed high trust in this source), personal doctors (53.5\%), satellite television (50.1\%) and radio (46.3\%) (Fig. 6). Between $50 \%$ and $60 \%$ of participants had moderate trust in information from local television, print and online news, family, friends, SMSs and email. Three in five participants (61.2\%) reported low trust in information from WhatsApp. Low trust was also reported in other social media and mobile chat services (52.0\% and $52.3 \%$, respectively). 
Public opinions by risk perception Participants were asked if they agreed or disagreed with various statements.

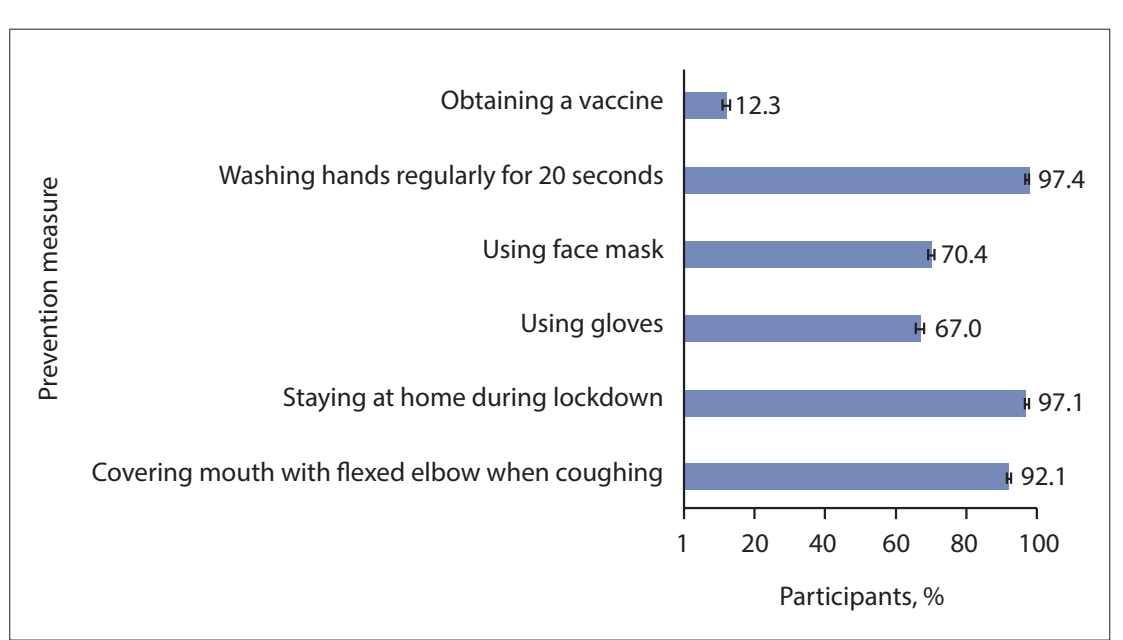

Fig. 2. Knowledge about COVID-19 prevention.

The percentages in agreement with each statement are presented by level of selfperceived risk of becoming infected with

\begin{tabular}{|c|c|c|c|c|}
\hline & Low, \% & Moderate, $\%$ & High, \% & $p$-value \\
\hline Total & 38.8 & 36.6 & 24.6 & \\
\hline Province & & & & 0.255 \\
\hline Eastern Cape & 38.6 & 36.1 & 25.3 & \\
\hline Free State & 36.4 & 33.0 & 30.6 & \\
\hline Gauteng & 40.0 & 37.3 & 22.8 & \\
\hline KwaZulu-Natal & 35.6 & 37.8 & 26.5 & \\
\hline Limpopo & 44.7 & 31.3 & 24.0 & \\
\hline Mpumalanga & 39.0 & 35.8 & 25.2 & \\
\hline North West & 38.8 & 36.5 & 24.6 & \\
\hline Northern Cape & 39.9 & 36.1 & 23.9 & \\
\hline Western Cape & 37.4 & 39.5 & 23.1 & \\
\hline Sex & & & & 0.648 \\
\hline Male & 39.1 & 36.0 & 24.9 & \\
\hline Female & 38.5 & 37.2 & 24.3 & \\
\hline Age group (years) & & & & $<0.001$ \\
\hline $18-29$ & 41.0 & 38.0 & 21.0 & \\
\hline $30-39$ & 37.8 & 36.6 & 25.6 & \\
\hline $40-49$ & 39.8 & 36.5 & 23.7 & \\
\hline $50-59$ & 42.3 & 32.4 & 25.3 & \\
\hline $60-69$ & 37.2 & 33.0 & 29.8 & \\
\hline$\geq 70$ & 24.3 & 44.4 & 31.4 & \\
\hline Race & & & & $<0.001$ \\
\hline Black African & 38.4 & 36.0 & 25.6 & \\
\hline Coloured & 38.9 & 38.0 & 23.2 & \\
\hline White & 41.4 & 39.6 & 18.9 & \\
\hline Indian/Asian & 38.7 & 38.0 & 23.3 & \\
\hline Employment status & & & & $<0.001$ \\
\hline Employed full time & 36.6 & 36.7 & 26.7 & \\
\hline Employed informal/part time & 40.0 & 34.9 & 25.1 & \\
\hline Student & 45.9 & 40.0 & 14.0 & \\
\hline Unemployed & 38.6 & 37.0 & 24.4 & \\
\hline Self-employed & 41.3 & 33.9 & 24.8 & \\
\hline Dwelling type & & & & $<0.001$ \\
\hline Formal & 39.2 & 36.8 & 24.0 & \\
\hline Informal & 30.0 & 34.2 & 35.8 & \\
\hline
\end{tabular}

COVID-19 (Table 4). Overall, 40.7\% and $47.9 \%$ of participants agreed that the SA health system and SA government, respectively, are capable of managing the COVID-19 outbreak. Over a quarter of participants (27.5\% and $26.6 \%$, respectively) thought that their local health facility and local supermarket were each capable of managing the COVID-19 outbreak Significantly fewer participants with a high or moderate self-perceived risk of COVID19 infection compared with those with a low self-perceived risk of infection agreed with the national health system, national government, local health facility and local supermarket capabilities of managing the outbreak $(p<0.001)$. Over $90 \%$ were in agreement that closing schools and restricting public gatherings would slow the spread of the virus, and $82.8 \%$ agreed that foreign nationals arriving by land, air or sea 


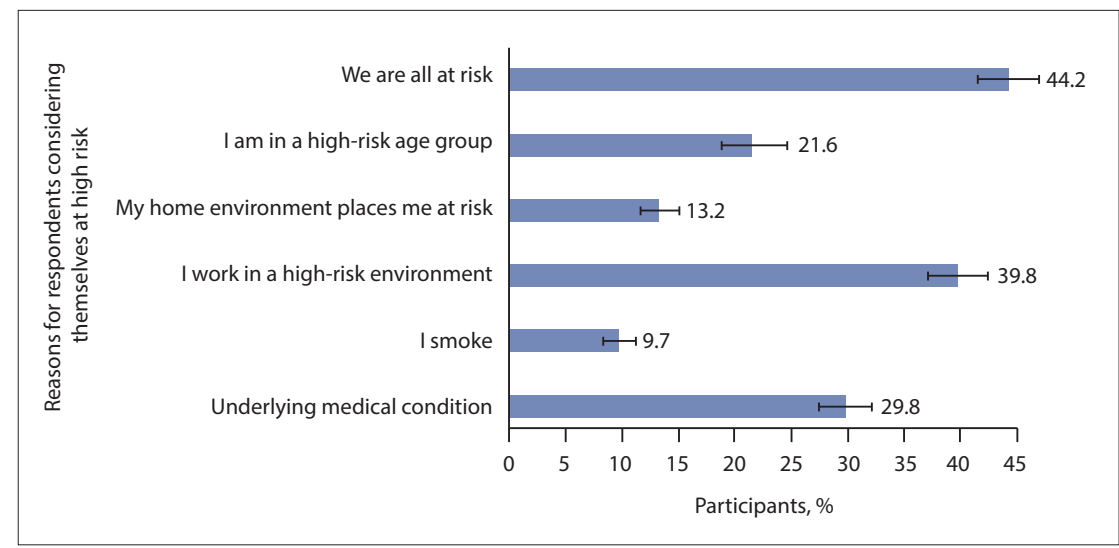

Fig. 3. Percentage of participants who perceived themselves as being at high risk of COVID-19 infection and their reasons for high-risk perception.

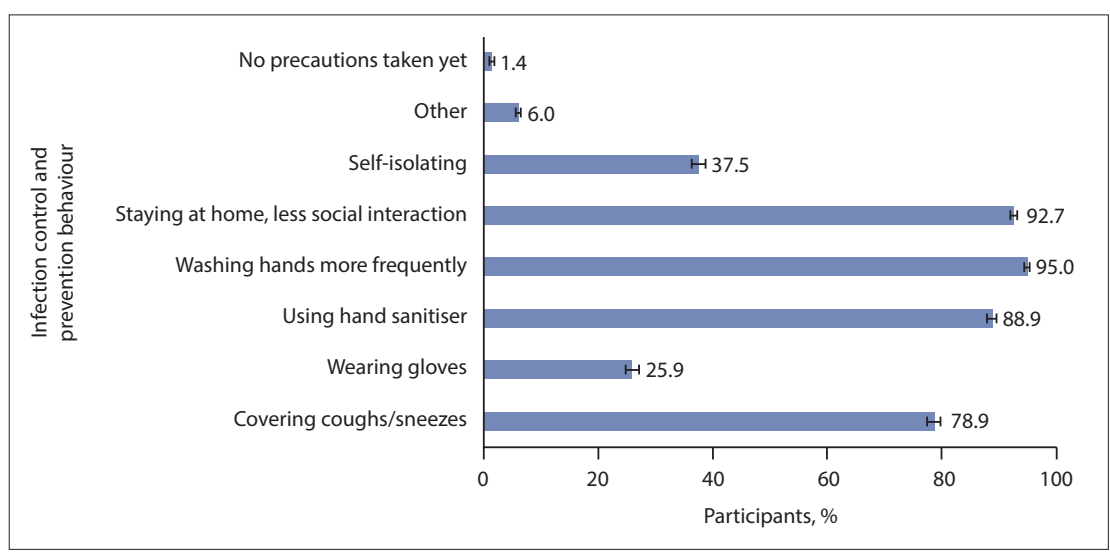

Fig. 4. Percentage of participants who reported various preventive behaviours during the week preceding the survey.

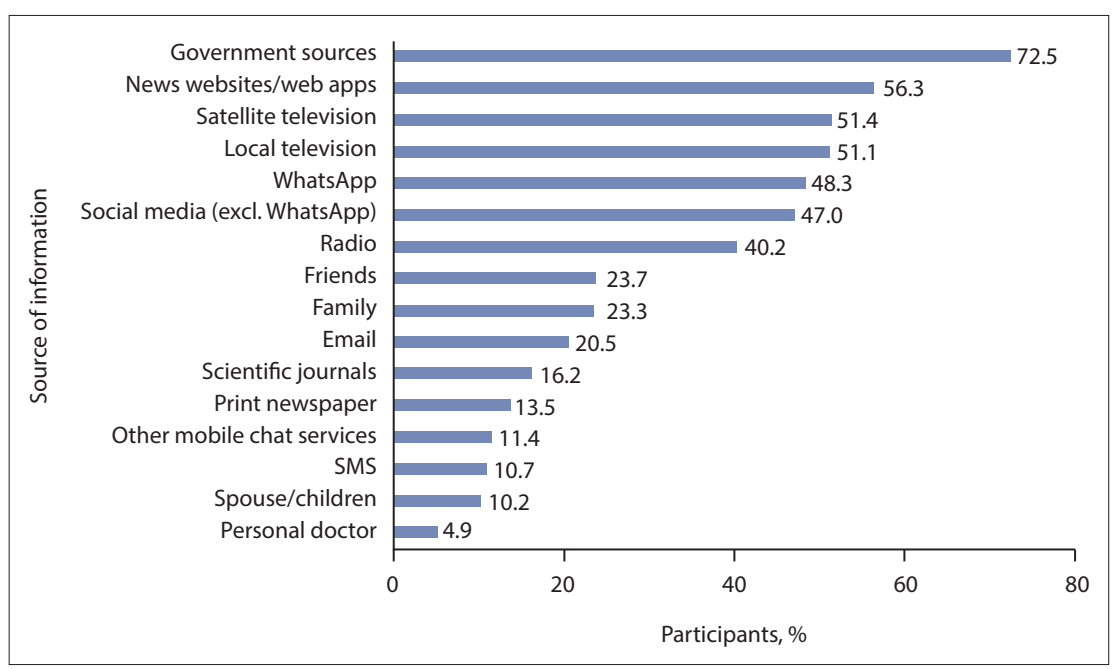

Fig. 5. Percentage of participants who reported each source they mostly use for information on COVID-19. (SMS = text message. $)$

who test positive for COVID-19 should be sent back to their home country immediately without exposing the SA population. Both these opinions were equally high across all levels of risk perception. Less than half of the participants (42.7\%) thought that there is too much media coverage on COVID-19 and that they could not keep up with it all. would self-isolate and call the national COVID-19 hotline, with this response being more prevalent in participants with low risk perception.

\section{Discussion}

The WHO has provided technical guidance on responding to COVID-19 outbreaks, but cautioned that the elements of its guidance may differ between countries, depending on their risk levels, public perceptions, local capacities and current situations. At the time of the study, SA was in its early stages of the epidemic and had implemented policylevel and public health interventions at the outset. It is crucial to obtain data on the nation's understanding of and response to the epidemic as early as possible. This need for data provided an opportunity to establish studies to assess public knowledge, attitudes and behaviours and to track these over time. Furthermore, these data could provide evidence for tailoring the communication and public health advice being provided to a heterogeneous population with health, socioeconomic, educational, sociocultural and spatial inequality. Moreover, many are at risk of infection because they live in crowded conditions, often with poor access to health and social services.

This survey is the first in a series of panel surveys to be conducted over the course of SA's epidemic, to provide ongoing insights to inform policy and address needs related to public communication. The study aimed to assess knowledge, attitudes, perceptions and behaviours regarding COVID-19, as well as responses to the policy and public health interventions during the first week of the lockdown. Owing to the nature of COVID19 outbreaks, the usual survey methods are not feasible. Rapid online surveys provide an opportunity to access a large number of people in a cost- and time-efficient way, thereby providing rapid insights into the COVID-19 response. Over a 7-day period, this survey attracted a high number of participants from across the country.

General knowledge of symptoms, incubation period, modes of transmission and prevention measures was very high. However, young people aged 18 - 29, people from informal dwellings, black Africans, part-time employees and students had lower knowledge. Self-perceived knowledge correlated highly with actual knowledge of COVID-19 modes of transmission, incubation period and symptoms. Notably, a small proportion perceived themselves as knowing enough or being up to date with the latest research, but did not correctly identify all the modes of transmission and symptoms. 
Most of the respondents identified shortness of breath, cough and fever as symptoms. The results from our study are consistent with findings in China, where $90 \%$ of respondents had good knowledge of COVID-19. ${ }^{11]} \mathrm{A}$ similar study among UK and US participants found that while there was good general knowledge of symptoms and transmission, there were also many misconceptions. ${ }^{[12}$

Knowledge of viral transmission from contaminated surfaces and from being in gatherings with infected people was lower than that for coughing and sneezing and for touching one's face after being in

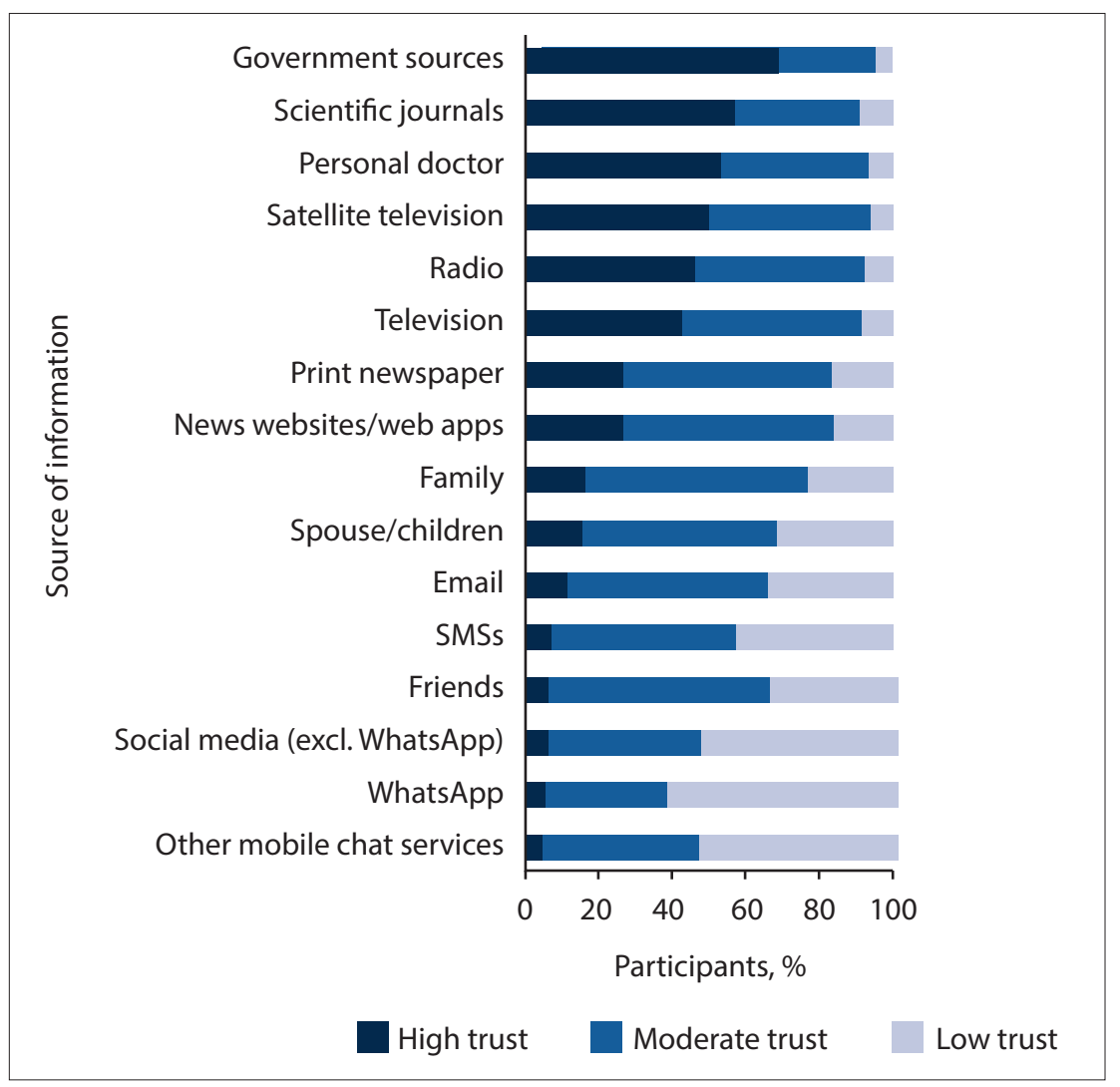

Fig. 6. Percentage of participants who reported trust in each source of information on COVID-19. $(\mathrm{SMS}=$ text message. $)$ contact with an infected person. This gap in knowledge needs to be corrected using targeted health education interventions, as these are important sources of community transmission in SA. The health education should carefully explain exactly how the process of transmission occurs, particularly because social distancing is a difficult behaviour and goes against human nature. With regard to knowledge of viral transmission from surfaces, health education interventions should reinforce the importance of regular cleaning and disinfecting of surfaces, particularly those that are touched by many different people, such as supermarket trolleys. It is also important for health education to counter fake news and misinformation. Health education messaging must also be accurately adapted and tailored as the challenges of the pandemic change over time, while also avoiding message fatigue.

In the absence of a question on residential area in this study, informal dwellings was used as a proxy for populations in crowded informal settlements. Participants from informal dwellings had a consistently lower prevalence of correct answers to all the knowledge items, but perceived themselves correctly as being at higher risk of contracting COVID-19. This vulnerable group needs tailored and targeted interventions as well as provision of enabling supplies such as water and hand sanitisers.

Effective communication and community engagement are key to the early and continued response to the COVID-19 pandemic. Regarding the multiple sources

Table 4. Participants who agreed with various statements by level of self-perceived risk of contracting COVID-19

\begin{tabular}{|c|c|c|c|c|c|}
\hline & Overall, \% & Low, \% & Moderate, $\%$ & High, \% & $p$-value \\
\hline $\begin{array}{l}\text { The SA health system is able to manage the COVID-19 } \\
\text { outbreak }\end{array}$ & 40.7 & 44.7 & 38.1 & 38.3 & $<0.001$ \\
\hline $\begin{array}{l}\text { The national government is able to manage the SA } \\
\text { COVID-19 outbreak }\end{array}$ & 47.9 & 52.4 & 45.7 & 44.1 & $<0.001$ \\
\hline $\begin{array}{l}\text { My local clinic/hospital is able to manage the SA COVID- } \\
19 \text { outbreak }\end{array}$ & 27.5 & 30.3 & 24.7 & 27.3 & $<0.001$ \\
\hline $\begin{array}{l}\text { My local supermarket is able to manage the SA COVID-19 } \\
\text { outbreak }\end{array}$ & 26.6 & 31.4 & 24.4 & 22.2 & $<0.001$ \\
\hline $\begin{array}{l}\text { Closing schools and restricting public gatherings will slow } \\
\text { the virus spread }\end{array}$ & 91.5 & 91.7 & 92.2 & 90.2 & 0.052 \\
\hline $\begin{array}{l}\text { There is way too much information in the media, and I } \\
\text { cannot keep up with it all }\end{array}$ & 42.7 & 41.5 & 42.4 & 45.3 & 0.075 \\
\hline The threat from COVID-19 is exaggerated in the media & 23.3 & 25.2 & 20.6 & 24.2 & 0.002 \\
\hline $\begin{array}{l}\text { Foreign nationals arriving by land, air or sea testing } \\
\text { positive for COVID-19 should be sent back to their home } \\
\text { country immediately without exposing the SA population }\end{array}$ & 82.8 & 82.2 & 82.1 & 84.7 & 0.081 \\
\hline $\begin{array}{l}\text { If I start showing symptoms and suspect COVID exposure, } \\
\text { I will self-isolate and call the national hotline }\end{array}$ & 92.3 & 93.9 & 92.0 & 90.4 & 0.001 \\
\hline
\end{tabular}


of available information on COVID-19, government communication as well as television and radio were highly accessed and trusted, providing an opportunity for government to distribute information over television and radio, thereby increasing health education coverage.

Participants with high self-perceived risk of becoming infected with COVID-19 expressed less confidence than those who regarded themselves as at low risk in the capabilities of government, the national health system, and local supermarkets and health facilities to manage the outbreak. Levels of panic emotion in a population can complicate the prevention and management of infectious diseases. ${ }^{[13]}$ It is therefore important for government and institutional communication to reassure and calm the public, particularly those at high risk of infection.

These research findings can be used by stakeholders to develop preventive behaviour messages, as part of an implementation research process. The messages can be tailored according to changing behavioural patterns as the epidemic progresses. As this study was conducted during the early stages of the epidemic, future research would need to investigate how various prevention behaviours influence or give way to others. For example, future research could investigate whether mask wearing leads to practising less social distancing or hand washing and sanitising. This would be important to understand, as prevention fatigue could possibly set in as the epidemic continues.

There was a high degree of personal responsibility associated with potential COVID-19 infection, and it is remarkable that $92.4 \%$ of participants said that they would self-isolate and call the national COVID-19 hotline if they believed that they had been exposed to the virus or showed symptoms. This altruism among South Africans in this time of crisis, coupled with their trust in government, are valuable assets in the country's efforts to overcome COVID-19.

\section{Study limitations}

This study has some limitations. A limitation of online surveys is that some subpopulations are less likely than others to have internet access and to respond to online questionnaires. Drawing a sample through online surveys is based on website visits. Inherently, the current survey achieved less participation from some population groups, such as unemployed people and those who live in informal dwellings, and there was no indication whether the survey tapped into the rural communities. We have attempted to overcome this limitation by benchmarking to the SA population. The disproportionate participation rates are also likely to reflect the digital divide and issues around connectivity and access to technology and the internet. Secondly, mask-wearing behaviour was not included in the questions. However, one of the strengths of the study is its use of rapid online surveys, which provide real-time results as the COVID-19 pandemic unfolds. ${ }^{[14]}$

\section{Conclusions}

Understanding knowledge, attitudes and behaviours of people facing the COVID-19 pandemic is crucial for guiding strategic policy. The study findings provide public understanding of COVID-19 as the phases of the country-level epidemic progress, and also directly inform communication needs and gaps.

\section{Declaration. None.}

Acknowledgements. We thank all the residents of South Africa who participated in and distributed the survey. We also thank Drs Natisha Dukhi, Razia Gaida, Thabang Manyaapelo, Whadi-ah Parker and Shandir Ramlagan for their contributions to writing the study report and at the early stages of the project; Ms Yolande Shean for logistical and administrative support; Dr Allanise Cloete and Ms Alicia North for work on the ethics proposal; and Profs Leickness Simbayi and Crain Soudien for their support in this work.

Author contributions. SPR conceived the study and led the writing. RS conducted the analysis, interpreted the results and drafted the manuscript. MM, SP, IN, SJ, TM, SS and KZ contributed to designing the analyses, interpreting results and drafting the manuscript. All authors read and approved the final manuscript before submission.

Funding. None.

Conflicts of interest. None.

1. World Health Organization. Statement on the second meeting of the International Health Regulations (2005) Emergency Committee regarding the outbreak of novel coronavirus (2019nCoV). 30 January 2020. https://www.who.int/news-room/detail/30-01-2020-statement-on-thesecond-meeting-of-the-international-health-regulations-(2005)-emergency-committee-regardingthe-outbreak-of-novel-coronavirus-(2019-ncov) (accessed 3 May 2020).

2. World Health Organization. Coronavirus disease 2019 (COVID-19) Situation Report - 76.5 April 2020. https://www.who.int/docs/default-source/coronaviruse/situation-reports/20200405-sitrep-762020. https://www.who.int/docs/default-source/coronavi
covid-19.pdf?sfvrsn=6ecf0977_4 (accessed 5 April 2020).

3. World Health Organization. Coronavirus disease (COVID-19) advice for the public. 4 April 2020. https://www.who.int/emergencies/diseases/novel-coronavirus-2019/advice-for-public (accessed
20 3 March 2020).

4. Nkengasong JN, Mankoula W. Looming threat of COVID-19 infection in Africa: Act collectively, and fast. Lancet 2020;395(10227):841-842. https://doi.org/10.1016/S0140-6736(20)30464-5

5. Statistics South Africa. General household survey: 2018. Statistical release P0318. Pretoria: Stats SA, 2019. http://www.statssa.gov.za/publications/P0318/P03182018.pdf (accessed 6 April 2020).

6. National Department of Health, South Africa. Update on Covid-19 (06th April 2020). https:// sacoronavirus.co.za/2020/04/06/update-on-covid-19-06th-april-2020/ (accessed 7 April 2020).

7. South African Government. Regulations and Guidelines - Coronavirus Covid-19. 26 March 2020 https://www.gov.za/documents/disaster-management-act-amendment-regulations-26-mar-2020-0000 (accessed 7 April 2020).

8. Nooh HZ, Alshammary RH, Alenezy JM, et al. Public awareness of coronavirus in Al-Jouf region, Saudi Arabia. J Public Health Med 2020 (epub 13 February 2020). https://doi.org/10.1007/s10389020-01209-y

9. Ipsos. Coronavirus: Opinion and reaction results from a multi-country poll. 12 - 14 March 2020. https://www.ipsos.com/sites/default/files/ct/news/documents/2020-03/tracking-the-coronavirushttps://wWW.ipsos.com/sites/default/files/ct/
wave-4-ipsos.pdf (accessed 7 April 2020).

10. Statistics South Africa. Mid-year population estimates 2019. https://www.statssa.gov.za/ publications/P0302/P03022019.pdf (accessed 5 April 2020).

11. Zhong BL, Luo W, Li HM, et al. Knowledge, attitudes, and practices towards COVID-19 among Chinese residents during the rapid rise period of the COVID-19 outbreak: A quick online crosssectional survey. Int J Biol Sci 2020;16(10):1745-1752. https://doi.org/10.7150/ijbs.45221

12. Geldsetzer P. Use of rapid online surveys to assess people's perceptions during infectious disease outbreaks: A cross-sectional survey on COVID-19. J Med Internet Res 2020;22(4):e18790. https:/ doi.org/10.2196/18790

13. Person B, Sy F, Holton K, Govert B, Liang A; National Center for Inectious Diseases/SARS Community Outreach Team. Fear and stigma: The epidemic within the SARS outbreak. Emerg Infect Dis 2004:10(2):358-363. https://doi.org/10.3201/eid1002.030750

14. Hurton S. The importance of understanding digital divides during the COVID-19 response. DAI Center for Digital Acceleration, 26 March 2020. https://dai-global-digital.com/covid-19-theimportance-of-understanding-digital-divides-during-the-pandemic-response.html (accessed 7 April importa.

Accepted 18 May 2020. 